\title{
Care, Control, and Color: A Conversation About Disparities in School Disciplinary Practices
}

\author{
Diana Wandix-White*
}

* Texas A\&M University - San Antonio, Department of Curriculum \& Instruction, San Antonio, TX, USA

E-mail: dwhite@tamusa.edu

\section{Article Info}

Received: May 12, 2020

Revised: September 9, 2020

Accepted: September 25, 2020

\section{$10.46303 /$ icsr. 2020.11}

This is an Open Access article distributed under the terms of the CC BY 4.0 International license. (https://creativecommons.org/licenses/by/4.0/)

\section{How to cite}

Wandix-White, D. (2020). Care, control, and color: A conversation about disparities in school disciplinary practices. Journal of Curriculum Studies Research, 2(2), 81-97.

https://doi.org/10.46303/jcsr.2020.11

\section{ABSTRACT}

Disciplinary practices teachers use in their classrooms frequently result in life-altering consequences for students who are historically marginalized and struggling to meet normalized standards of academic success. Research suggests teachers often lack the skill needed to connect with students, manage their classrooms, and administer corrective action that is equitable, reasonable, and effective without being excessive and detrimental to the student's future. This disconnection and lack of judgment is frequently attributed to 1 ) the cultural mismatch that exists between the majority U.S. teacher who is a young, White female, and the growing diverse population of students; 2) teachers' deficit view of students of color, their families and communities; and 3) deficient preservice teacher training that does not equip future teachers with the culturally relevant pedagogical skills needed to meet the needs of today's students. Employing the qualitative research methods of interactive interviewing and parallel stories, an African American, veteran teacher and a young, White pre-service teacher explore the topic of disciplinary practices at the intersection of race, ethnicity, and a classroom culture of care in the k-12 U.S. classroom.

\section{KEYWORDS}

School discipline; Teacher-student relationships; Culture of care; Interactive interviewing; Parallel stories 


\section{INTRODUCTION}

Every time America thinks the color divide is fading, someone turns on a UV light and all the nasty stains, residue, and hidden welts reappear. Unfortunately, many of the lingering wounds are festering in the U.S. education system. This is particularly evident in the disparities present in school disciplinary practices. Students of color are often more likely to be "differentially selected for discipline consequences" (Gregory et al., 2010, p. 62), and African American and Latino students, especially, are subject to extreme punishment for less than extreme behavior. In fact, in the U.S., African American students are consistently suspended and expelled at rates two to three times greater than other students (Mitchell, 2014; Porter, 2015; Schiff, 2018; Skiba, 2014); "Black students are more likely to be suspended for discretionary reasons, rather than they committed infractions where suspension was mandatory punishment" (Nelson, 2015, para. 13); and "school administrators are three and a half times more likely to suspend African American students than White students, even for the same non-violent offenses" (Porter, 2015, p. 59). Many scholars have researched this issue (Alexander, 2010; Dupper, 2010; Gonzalez, 2012; Herbert, 2015; Mongan \& Walter, 2012), providing evidence that this condition is unfeigned. Most often, right or wrong, the classroom teacher bears the blame for this injustice. If these inequitable disciplinary practices, however, are assumed to be the result of cultural misunderstandings and inadequate classroom management training rather than a conscious act of racism, a conversation can be had that could change the trajectory of this phenomenon. And as Brown and Isaacs (2001) note, intimate conversations can generate insight that spreads to larger groups, "carrying the seed ideas for new conversations, creative possibilities, and collective action" (p. 1), essentially acknowledging conversation as a path to large-scale change.

During a short-term study abroad trip to Guanajuato, Mexico, such a conversation took place between an African-American, veteran teacher with more than 20 years of secondary level teaching experience, and a young, White pre-service teacher in her senior year of an undergraduate degree in education. While the interaction began as a simple conversation on a bus ride in Mexico, it developed into parallel stories gleaned from an interactive interview, during which both participants ask questions, share narratives, and engage in dialogue with one another as a way to explore the topic of disciplinary practices at the intersection of race and ethnicity and a classroom culture of care in the k-12 U.S. classroom.

\section{Context}

The provocation for the conversation occurred during a meeting between a university study abroad group and several rural Mexico school leaders. Following are the abbreviated field notes from the encounter:

[June 2017] On this morning, all eighteen student members of the University study abroad group, and the two overseeing faculty members, went to [a local school] to meet with rural principals and school leaders. We arrived at the school, which was surrounded by a metal fence. There was an open courtyard in the middle, one small and two mid-sized 
buildings, and situated on one end of the courtyard, a few picnic tables under full, green trees. We were greeted by our hosts, entered the middle building, and were seated in child-size chairs lined along the walls. After we all introduced ourselves to one another, some in Spanish, others in English-both translated by our hosts, we were split into groups to talk about education in several different contexts. My group included Madison Marshall (pseudonym), [one other University student], one of our hosts, and two male principals from two Mexican primary schools. At the end of our conversation, one of the gentlemen asked how we deal with disciplining students in the U.S. Madison and [the other University student] responded by telling them if the teachers deem a student's behavior as a discipline problem, the student is often sent out of class to the administrative offices. They stated that once there, there is generally a discipline process the student goes through before being able to return to class. I commented that it is important to build rapport with students very early on: "They need to know that you care about them and that you will not stand for an environment that is not conducive to learning for the entire class." I mentioned that many times the school disciplinary procedures are responsible for what is called the school-to-prison pipeline in the U.S. I shared that the school-to-prison pipeline mostly affects African-American and Hispanic students due to subjective discipline. Upon returning to the bus after the meeting, Madison asked if she could talk with me about my comments. With the conversations of our twenty or so colleagues going on around us, and the rugged beauty of the landscape breezing by our window, Madison and I began to talk about school, race, culture, and discipline.

\section{Relevancy}

Madison was sincerely concerned about her ability to be sensitive to the fact that when children of color are sent out of a classroom, the results can and often are much more drastic than when White students are reprimanded by removal. She wondered if her background and lack of culturally relevant teacher training would render her blind to, or even a contributor to the systemic racism that exists in America's schools. While Madison's concerns represent her personal narrative, they may resonate with the majority of U.S. educators who share similar characteristics and are struggling to meet the needs of the new student population in their classrooms.

\section{METHODOLOGY}

There are plenty of statistics and figures that suggest disparities in the treatment of certain student populations. Over the years, this type of information has led to various laws, acts, policies, and reforms that have only added to the plethora of problems with America's education system (Kauffman, 2002; Miron \& St. John, 2003; Ravitch, 2014). As these attempts to leave no child behind failed, researchers and policy makers began to ask why. They needed 
to hear the stories of students, teachers, parents, administrators, and other stakeholders to put meat on the bones of the data. Qualitative research provides the why and how. This study employs two qualitative research methods to capture and interpret the rich experiences of the authors: interactive interviewing and parallel stories.

\section{Interactive interviewing}

Discomfort can arise when we reflect on our own biases and predispositions, and attempting to share these reflections can create additional anxiety and stress. However, when a researcher acts as a co-collaborator with participants, the communication process may become less daunting. Interactive interviewing gave both parties in this study the opportunity to gain an indepth and intimate understanding of each other's internal and external experiences with the sensitive topic of how race and ethnicity affect the relationship between teachers and their students. Ellis (2012) makes the following statement about interactive interviewing: "Emphasizing the communicative and joint sense making that occurs in interviewing, this approach involves the sharing of personal and social experiences of both respondents and researchers, who tell (and sometimes write) their stories in the context of developing relationships" (p. 444). Conversations during our seventeen-day study abroad, two face-to-face discussions after our return, and several electronic communications created ongoing interactions between Madison and me and allowed us to be open and vulnerable with one another regarding the topic at hand. Furthermore, although I am considered the researcher, we worked to establish a collaborative relationship, rather than a hierarchical association, by treating our discussions as casual conversations instead of formal interviews. We engaged in reciprocal question and answer dialogue, avoiding any semblance of an inquisition. Finally, we kept meticulous records of our interactions in order to strengthen the validity and reliability of our work.

\section{Parallel stories}

In America's current state of division, it is important to recognize the parallel stories that exist between individuals who, on the surface, have no intersecting lines between them. Parallel stories, a methodology that evolves from Clandinin's (1986) narrative method, allows us to reveal conceptual and theoretical understandings that other methodologies do not necessarily allow (Craig, 1999). By utilizing parallel stories as methodology, we were able to gain and present "insights relating specifically to stories of school, insights relating specifically to teacher stories, and insights relating specifically to the relationship between the two types of meaning recovery" (Craig, 1999, p. 407). It allowed us to reflect upon and verbalize our stories in relation to the single, ever-changing narrative of school disciplinary practices.

Note: MM is Madison Marshall, participant. DW is Diana Wandix-White, researcher and participant. 


\section{CONVERSATIONS IN BLACK AND WHITE}

\section{Positionality}

MM. I am a non-Hispanic White female in my 20s with an evangelical Christian, politically conservative, middle class background. I, therefore, identify with a vast majority of the teachers presently coming out of teacher preparation programs. I hope to offer my perspective as such and share some of my journey in the pursuit of understanding the roles of cultural differences and equity in the classroom. I am currently a senior in the education department of a 4-year research university in the South-Central region of the U.S., pursuing a degree in middle grades math/science education.

DW. I also identify as evangelical Christian; that's something we have in common. However, I rarely put a name to my political stance, as my views are varied; but for the sake of parallelism, I'd say I am an African-American female in my 40s who leans toward conservative liberalism. I also come from a middle-class background, though in my earliest years, I didn't always live in middle class surroundings. I'm currently a third-year doctoral student at a public Research I university in the South-Central region of the U.S. I'm studying curriculum and instruction, with an emphasis in urban education.

What the literature says. Positionality considers intersecting variables, such as race, ethnicity, gender, socioeconomic status, religion, and other social diversities (Moore, 2008). Lei (2006) comments that "all teachers need to critically reflect on their own positionality within the system of Whiteness and how their cultural lenses affect their pedagogy" (p. 85). Clearly, both Madison and I are aware that our list of internal and external characteristics are with us each time we enter a classroom and interact with our students. However, it is conceivable that many educators, including the two of us, do not realize the extent to which certain aspects of positionality affect how we relate to our students, especially those with whom we are culturally mismatched. Much of the literature regarding the effects of positionality on teacher-student relationships and teacher disciplinary practices focuses on issues of whiteness and white privilege, this owing to statistics that assert anywhere from 80 to 90 percent of the public k-12 teacher population is White, and the student population is steadily growing more and more diverse (National Center for Education Statistics, 2017; U.S. Department of Education, 2016). Ladson-Billings (2001) stresses how important it is that the majority teacher examine this social positionality as it intersects with that of their students:

Typically, White, middle-class prospective teachers have little to no understanding of their own culture. Notions of Whiteness are taken for granted. They rarely are interrogated. But being White is not merely about biology. It is about choosing a system of privilege and power. (p.81)

Some scholars suggest that the majority White, middle class teacher makes minimal effort to make inequity, intolerance, or powerlessness problematic and open to discussion (Gollnick \& 
Chinn, 2016; Nganga, 2015); they understand their position of power as it relates to the very generic idea of teacher over student, but may fail to acknowledge the idea of White privilege and, therefore, fail to address the problems associated with this aspect of their power.

White teachers are not alone in this matter of positionality. "Teachers of color occupy unique positionalities when they teach students of their self-identified community in public schools" (Heer, 2015, p. 369). Conversely, teachers of color often feel pressure when teaching students of color, because they fear not living up to the expectation that they will be able to meet the student's needs simply because they are culturally matched (Heer, 2015). Furthermore, when teachers of color teach a predominantly White student body, the teacher may deal with issues of identity and acceptance (Kersey-Matusiak, 2004) which act as barriers to relationship development.

Ultimately, positionality informs both the theorizing and the practice of education, and teachers must be critically conscious of their positionality as they consider how they will interact with students.

\section{Theory Versus Practice}

MM. This summer, I had the opportunity to go with the University's Department of Education to Mexico for two weeks. During this time, our group met with some of the local principals. I was in a small discussion group with Mrs. Wandix-White. One of the principals asked us how we would approach a situation in which a student repeatedly engaged in poor behavior. One of the other undergraduate students and I shared what we had learned in our teacher preparation courses. We talked about Behavior Intervention Plans, 3-Tier Programs, etc. After we shared, Mrs. Wandix-White offered a different perspective, one that I had never heard before. She said the plans and programs that teachers are often taught to implement only work for a specific type of student and often fail minority students. Our time was cut short then and we had to end our conversation. I was left thinking, "how can I be wrong about this? I gave all the right answers. I've made all A's in my courses. This is what they taught me! How can she say that it could fail?" I decided to swallow my pride and ask her to explain this new concept to me. I asked why the recommended behavior strategy system fails students of color.

DW. Relationship. Behavior modification plans, punishment and reward systems, intervention tactics - none of those things work with any consistency if the relationship between teacher and student is negative or nonexistent. I have had my own issues with students in the past, and when I reflect, I see that it was always because I neglected to establish an authentic, caring relationship with that student. On the other hand, I remember fellow teachers complaining about a particular student behaving poorly in class, but in my class the student was cooperative, productive, and successful. I attribute that to having built a rapport with him, respecting him as a human being, and showing him that I cared about more than just his grades. My fellow teachers had rigid behavioral expectations and doled out punishment without first 
understanding the situation or adapting their response to the specific needs of the student. Yes, the student was African-American, I'm African-American, and the other teachers were White. While I believe that played a part in the relationship dynamics, I do not believe that cultural mismatch has to equate to relational negativity; just as I do not believe that cultural matching necessarily equates to positive teacher-student relationships. But when teachers do not initiate positive relationships with students and understand cultural differences that affect behavior, they tend to overreact or misread certain behaviors, which causes them to fear losing control of their classroom and hand out punishments that are far harsher than necessary. Students of color are the most frequent recipients of this inequity.

What the literature says. Children and adolescents tend to operate mostly on feelings and social influences (Steinberg, 2005); if they like a teacher, they will work hard to be a "good" student and make that teacher proud. On the other hand, students who have conflicted relationships with teachers "tend to like school less, experience less self-direction, and show lower levels of cooperation in classroom activities" (Krstic, 2015, p. 168). Positive teacher-student relationships may be even more essential in urban school settings where students face the additional challenges associated with high-poverty environments (Murry \& Malmgren, 2005). Studies have found that affirming, authentic teacher-student relationships, and the connection between positive relationships and academic achievement and resilience is stronger for ethnic minority students (McCormick et al., 2013; Roorda et al., 2011), and "the protective effect of teacherchild relationships on academic achievement may be stronger for lower-income and racial/ethnic minority students, compared to more affluent, White students" (McCormick et al., 2013, p. 612).

In fact, African American and Hispanic students appear to benefit more from close relationships with their teachers than do White students (Roorda et al., 2011; Sabol \& Pianta, 2012). However, in school settings, where the student population is represented by a high percentage of children of color who come from low socioeconomic backgrounds, but the teachers are still mostly middle-class White females, there exists that cultural mismatch that encourages a distrust and separation, making affirming relationships challenging and leaving students feeling disconnected from their teachers (Davis, 2003). Ultimately, teachers who are supportive and have positive, caring relationships with their students are more apt to have students who avoid negative behavior (Bergin \& Bergin, 2009; Sabol \& Pianta, 2012). So, when it comes to "maintaining control" of student behavior, it is the relationships teachers have with students, more so than any policies and procedures, that encourage students to actually follow the rules.

\section{Equal Versus Equitable}

MM. Prior to my conversation with Mrs. Wandix-White, all my knowledge of behavior management was based in Behavior Intervention Plans (BIP), vague knowledge of different 
programs such as Conscious Discipline or Capturing Kids' Hearts, and behavior contracts. I had frequently heard of individualization of instruction but never of individualization of behavior management. Never had I considered that what is "fair" is not the same system of punishment or reinforcement for each child. I will share more of my personal background to better explain my perspective on this topic. I attended a private school in which the majority of students were, by far, White. Furthermore, each student had nearly identical home lives, future goals, parental styles and expectations, etc. Because of this, teachers at my school could easily implement one behavior strategy and find success with all but maybe one student. In all my life, what was "fair" was what was "equal." I first heard the concept of equity in the classroom in a course called "Diversity Consciousness" in the spring of 2015. My inner capitalist background did not like this at all. To think that some students would receive more or less support and resources depending on their unique situation seemed unfair to me, because I had never had the experience of being the one with less or no empowerment. To me, what was fair was everyone receiving the same tools. If everyone had the same tools, everyone had an equal chance of reaching the goal. I came to realize, however, that my interpretation of things was greatly clouded by white privilege. Oooooh I did not like the concept of equity. The more I came to realize my privilege, the more frustrated I became. Despite myself, I started to understand that giving everyone the same tools does not mean they have equal opportunity to reach the same goal. Some people get to start the race one hundred miles ahead of others. If I really wanted to care for students, it was time for me to stop treating them the same way and start treating them in the way each one, individually, needs. To be honest, this is incredibly difficult for me. So much of my instinct goes against this and I definitely prefer my own cultural norms and attitudes. However, I am working to build a habit of treating people with equity because I know its immense value.

DW. In my youth, I attended both urban and suburban schools. Many teachers in the urban schools showed they "cared" by lowering expectations, praising my artificial successes, and ignoring misbehaviors which sometimes created an atmosphere that made teaching and learning challenging; while my suburban school teachers maintained universal high expectations but failed to provide me with the tools I needed to reach them, and often disciplined instead of aided me when I lacked academic understanding. Later in life, these divergent experiences highlighted for me the difference between equality and equity. Hence, one of my favorite images is a modified version of Craig Froehele's equality/equity meme (2012). Froehele created the meme to illustrate his point in a political argument that "'equal opportunity' alone wasn't a satisfactory goal and that we should somehow take into consideration equality of outcomes" (Froehle, 2016). The meme depicts three individuals attempting to watch a baseball game happening on the other side of a wooden fence. To represent equality, the first image shows each person on a crate of the same height. Of course, they are getting equal treatment by each getting one crate to add height, but now the taller one sees even better, the second is high enough to peek over the top, and the third's view is still blocked by the fence. In the second 
frame of the meme, each of the three are given crates of different height to make it possible for each to have equal access to the game; in this instance, they are being treated equitably. However, in the revised meme, there is a third frame. In this frame, the cause of the inequity, the wooden fence, has been removed. Now each of the three individuals can stand on his or her own two feet and still have access to the end goal: watching the baseball game. This meme is a befitting symbolic representation of the disciplinary practices in America's elementary and secondary schools. Things like unilateral discipline practices, zero tolerance policies, and colorblind philosophies act as the equal sized crates that, theoretically, place everyone on equal footing; but the subjectivity with which unilateral punishment is administered, and the lack of cultural awareness and sensitivity associated with colorblindness creates further inequities. It is a difficult concept, but I think our heads can rationalize equality, but it is our hearts that have to acknowledge the need for equity. As an African-American woman, I can see it, and I can feel it. It is easier to fight for justice when you have been a victim of injustice. It is just easier to see the need for something different.

What the literature says. In theory, blanketed, rigid disciplinary policies (zero tolerance policies, for example) remove bias and limit discrimination in discipline practices because they do not allow the discipliner to exercise discretion or be subjective when administering punishment. In practice, these types of policies have proven to be inequitable and detrimental to certain populations (DeMitchell \& Hambacher, 2016). When the act of misconduct itself can be viewed subjectively, scholars suggest that students of color are judged more harshly (Herbert, 2015; Mitchell, 2014). The cultural mismatch between the majority of America's teachers and the U.S. student population often creates situations in which home and school culture are at odds; and in this society where all behavior is measured against a White, middle-class, Christian code of conduct it is easy for subjective interpretations of misbehavior to result in biased judgements and excessive punishment. Disparities between Black and White student discipline, in particularly, occur most often in discretionary categories, like insubordination and insolence (Skiba, 2014); and these discrepancies may be caused in part by lack of cultural sensitivity or inadequate training in culturally responsive classroom management.

\section{Propensity Versus Preparation}

MM. Many of my peers in my education courses feel my same deep love for children and desire for their success. I would not doubt the intentions of any of my classmates. However, nearly all of my classmates are female, and nearly all are White. Many of us have not been in environments in which we would have been exposed to the perspectives of people of color who have been mistreated by the educational system, either through bad intentions or good intentions gone wrong. Because of this, we teach to "us"- "us" being White students of white culture. We want our students to succeed but are either unaware that our classroom management style is frequently harming students of color, or we are aware but do not know what to do because we have never had to live the experience of a minority in the United States. 
So many people feel awkward having discussions about these matters and this further alienates us from students and families of other cultures. This alienation prevents us from ever having that genuine rapport that Mrs. Wandix-White shared with me as her true treasure in mastering classroom management. I believe that many, if not all, of the pre-service teachers at University crave this cultural understanding and sensitivity but don't know how to achieve it. The fear of being disrespected as pre-service and first year teachers runs deep in many of us. Many of the cultural norms and habits of minorities are interpreted as disrespect and thus responded to with a harshness borne out of fear of losing control. Because we have not received adequate training in how to adapt our behavior management to specific cultures, backgrounds, classes, and ethnicities, we default to our own experience and fail to treat students equitably.

DW. I mentioned relationship before, and I believe it is paramount; but it also takes training and preparation, and if your certification program did not prepare you to teach and connect with all students, then you have to be willing to seek professional development or mentoring that will help. You have to do it yourself. I tend to agree with Madison-I do not think any teacher enters the profession wanting or intending to emotionally or intellectually harm their students. But if we ignore the problem, disregard the conversation, or neglect seeking additional training, we are, ultimately, causing great harm to our students. So, I am glad that we are having this conversation. I have no doubt that there are teacher training programs and professional development opportunities out there that authentically seek to train and develop qualified teachers not only to know their content area and understand the complexities of instruction and classroom management, but also to appreciate the diversity and recognize the importance of valuing student differences. We, teachers, just have to do a bit of research to find legitimate opportunities to gain authentic training and, most importantly, to engage in critical selfreflection to determine if we need to focus on external growth and development, like culturally relevant curriculum content, diverse instructional designs, and varied lesson plans; or internal growth and development, like cultural sensitivity, respect and appreciation for all students, and general humanitarianism.

What the literature says. One sure answer to how do teachers develop authentic cultural sensitivity, effectively manage their classrooms, and successfully navigate school disciplinary policies in order to execute equitable disciplinary practices that eliminate racial disparities in school discipline is proper training. Pre-service teachers need legitimate pre-service teacher training that truly prepares and equips them to meet the needs of all students. The demographics of the U.S. demand that prospective teachers learn to effectively educate culturally, linguistically, socioeconomically, and racially diverse students. Regrettably, however, many new teachers who have completed pre-service education programs enter their classrooms with minimal prior contact with racial groups other than their own (Milner et al., 2003), and they exit these programs with no greater cultural knowledge or understanding. While students of color account for nearly half of all students in public schools, the teacher workforce 
is still predominantly White "and so teacher training programs are increasingly trying to figure out how to bridge this divide" (Romo, 2016). Goodwin (as cited in Villegas \& Lucas, 2002) states, "the typical response of teacher education programs to the growing diversity among $\mathrm{K}-12$ students has been to add a course or two on multicultural education, bilingual education, or urban education" (p. 20), but since these added courses are often optional, "students can complete their teacher education programs without receiving any preparation whatsoever in issues of diversity" (Villegas \& Lucas, 2002, p. 20). Milner (2015) points out that professional development and teacher education programs are not effectively preparing teachers to be managers of their classrooms, let alone effective teachers of diverse or urban classrooms. Milner also discusses a study showing that when preservice teachers were given training on management strategies to use in diverse classrooms, many teachers were still unsuccessful because of "subtle forms of racism and strong cultural norm that impacted the teachers' practices in the study" (p. 576). The difficulty may lie in preparing teachers to be effective managers in diverse school settings while simultaneously helping them to avoid accepting the fallacies and stereotypes regarding what it means to teach, learn, and manage in diverse classrooms.

Ultimately, a lack of effective pre-service training, especially in the area of culturally responsive pedagogy and adequate field experience, creates teacher ineffectiveness and magnifies the cultural mismatch that exists between the majority teacher pool and the growing multicultural student body that exists in America's schools.

\section{DISCUSSION}

\section{Insights Relating to Stories of School}

According to the National Center for Education Statistics (n.d.), there are well over 90,000 public k-12 schools, and over 34,000 k-12 private schools in the U.S. Thus, there are over 120,000 unique school narratives to be told. Madison attended a private, predominantly White school where the students, families, and surrounding communities were homogeneous. There were very few students of color in her school; none in her inner circle of friends. Madison's understanding of behavior and school discipline emerged as fundamental aspects of her school experiences in this shielded private school where she was with essentially the same group of students for 12 years. Parents were actively involved and counted on to instill and uphold the school's code of conduct. As Madison stated, because "each student had nearly identical home lives, future goals, parental styles and expectations" teachers and administrators were able to "[implement] one behavior strategy and find success with all but maybe one student." This is rarely the case in urban or other public school environments where the diversity of students, variability of socioeconomic status, variances in family dynamics, and miscellany of life experiences makes any type of standardized corrective processes often unreasonable and frequently ineffective. The founding stories of these divergent types of schools are deeply 
rooted in their communities (Craig, 2000), communities that may only be separated by miles, but are essentially worlds apart.

\section{Insights Relating to the Relationships Between Personal and Institutional Narratives}

As stated in Craig (1999), the parallel stories methodology allows us to determine the extent to which Madison's and my teacher stories are uniquely situated within the stories of schooling we have both experienced. I attended both extremely diverse public schools and predominantly White public schools. I have taught in a variety of school settings: public urban, public suburban (as a substitute), private Christian, and private secular. As a student, I recall being sent out into the hall for "speaking out of turn," while my White classmate was merely told to be quiet. As a teacher, I specifically witnessed the inequitable treatment of an African American male and a Hispanic female at the hands of an all White administrative team. These experiences surely influence my attitude, beliefs, and practices regarding school discipline. I recognize that at times I have been more lenient on students of color, because I have assumed they have received the opposite consideration at the hands of other teachers with whom they are culturally mismatched. Likewise, Madison's experiences as a student in a school that adopted the policy of treating their homogeneous student body virtually all the same shaped her experiences and influenced what she came to know (Craig, 1999). This is illuminated by her initial dislike of equity in favor of equality. Madison planned to treat all her students the same, no matter what.

Ultimately, our respective narratives "revealed the past residue of human experience on [our] professional landscapes and showed how such residue pervades school contexts" (Craig, 1999, p. 408), manifesting itself in our beliefs and ideas about school disciplinary practices. Fortunately, our ongoing conversation helped both of us recognize that our previous school experiences have a definite impact on our present state of mind; and it may be time to challenge our respective mindsets in order to better serve our future students.

\section{Insights Relating to Teacher Stories}

(In Madison's words:) For my senior student teaching experience with University, I was paired with a mentor teacher with whom I shared a similar background in terms of education, belief system, socio-economic status, and ethnicity. Being so inexperienced, I attempted to mimic her in every procedure and attitude toward our fifth-grade students. (We were both white females with a student population of $60 \%$ Hispanic, $20 \%$ white, $17 \%$ African American and $80 \%$ economically disadvantaged). Her management style was one where she was able to rest on prior relationship building and "intimidate" students into adhering to her expectations. This did not work for me due to my lack of prior relationship with the students, my entrance into the classroom in the spring semester, and my very unintimidating [sic] personality. The gap between my culture and the culture of my students quickly became apparent to me, and it led me to view the enforcement of classroom expectations as a daunting task. I reflected on my conversation with Mrs. Wandix-White and recalled that this view could easily lead to me becoming harsher on the students who I feared would be a threat to my authority without first seeking to study 
their backgrounds and understand them. While this still remained a struggle for me, I was much more aware of the habits I developed in the treatment of my students, for example, who I most frequently redirected, who I had relationships with, who I entrusted with leadership, etc. While I first sought to emulate my mentor teacher, I started to distance myself from her management style; not because it was inadequate, but because it was not consistent with my personality. To develop genuine relationships with my students, I had to be honest about who I was, even in discipline.

Now as a first-year teacher, I teach first grade at a Title I school with a student population that is $83 \%$ Hispanic, $5 \%$ white, and $5 \%$ African American. $88 \%$ of the students are economically disadvantaged. I find myself once again faced with the challenge of building deep relationships based on sincere care while attempting to understand students with backgrounds very different from my own. Many of my coworkers share similar backgrounds and cultures with the students, and I have seen how quickly trust is established between them. These teachers have influenced my practice as a teacher by modeling an attitude of humility when approaching students with misbehavior - not looking to prove their dominance, but genuinely looking to help the student better express his or her problem. The power of that attitude has resulted in the development of wonderful relationships and a more peaceful, positive atmosphere than I could have ever expected.

\section{Implications for Teacher Education}

The American Psychological Association Zero Tolerance Task Force (2008) listed findings suggesting that the "disproportionate discipline of students of color may be due to lack of teacher preparation in classroom management, lack of training in culturally competent practices, or racial stereotypes" (p. 854). Classroom teachers are at ground zero of the student disciplinary chain of events since the classroom or a campus area that teachers monitor is most often where student misconduct is witnessed, addressed, and reported. When the classroom teacher fails to effectively address students' minor infractions on his or her own, students, especially students of color, can end up facing severe consequences for petty acts of misconduct. State teacher training programs, as well as school districts and individual schools must provide pre-service and active teachers with ongoing culturally responsive education and effective classroom management training. In order for such training and development to be effective, however, it must include opportunities for teachers to examine their own perceptions, biases, and predispositions that affect the way they interact with their students.

In addition to classroom management skills, teachers must learn how to initiate and maintain positive relationships with students; relationships characterized by social and academic support, high expectations, authentic caring, and genuine interest. Sadly, however, teaching has become so focused on rigid curriculum and high-stakes testing that the endless list of things to do overshadows the practice of care and establishing relationship (Cooper, 2004; Narinasamy \& Mamat, 2013; Wilde, 2013). At minimum, there is a need to restructure teacher 
preparation programs to include training that promotes a commitment and capacity to care for all learners, paying attention to each student's unique needs.

\section{CONCLUSION}

The stories the majority U.S. teacher lives by are stories of the young, White, middle-class female who is influenced by all the rights and privileges (whether subtle or overt, accepted or rejected, imagined or unimagined) that accompany those characteristics. Their identities inform their teaching, just as students' identities inform their learning. The knowledge individual teachers and students construct is predicated on their lived experiences that are greatly influenced by each one's identity and position within specific social contexts. This knowledge also extends to how teachers view misbehavior and how aggressive or lenient they are regarding certain subjective student misconduct. This would also suggest that the disciplinary actions teachers take are likely based on their personal values, thoughts, experiences, and beliefs about appropriate and inappropriate classroom behavior.

Madison's willingness and desire to understand disparities in school disciplinary practices due to systemic racism in America's schools, her courage to explore this issue with someone so seemingly dissimilar from herself, and this resulting manuscript do in deed create "seed ideas for new conversations, creative possibilities, and collective action" (Brown \& Isaac, 2001, p. 1). Thus, while the dialogue and critical self-reflection presented throughout this article represent my and Madison's personal narratives, we hope that our story contributes globally to redefining the ways in which teachers conceptualize and create a culture of care and equitable disciplinary practices in their classrooms.

\section{REFERENCES}

Alexander, M. (2010). The new Jim Crow: Mass incarceration in the age of colorblindness. New York, NY: The New Press.

American Psychological Association, Zero Tolerance Task Force Report. (2008). Are zero

tolerance policies effective in the schools? An evidentiary review and recommendations. American Psychologist, 63(9), 852-862.

https://psycnet.apa.org/doi/10.1037/0003-066X.63.9.852

Bergin, C., \& Bergin, D. (2009). Attachment in the classroom. Educational Psychology Review, 21, 141-170. https://doi.org/10.1007/s10648-009-9104-0

Brown, J., \& Isaacs, D. (2001). The world cafe: Living knowledge through conversations that matter. Retrieved from The Systems Thinker, 12(5):

https://thesystemsthinker.com/the-world-cafe-living-knowledge-throughconversations-that-matter/

Clandinin, D. J. (1986). Classroom practice: Teacher images in action. Philadelphia: The Falmer Press. 
Cooper, B. (2004). Empathy, interaction and caring: Teacher's roles in a constrained environment. Pastoral Care, 12-21. https://doi.org/10.1111/j.0264-3944.2004.00299.x

Craig, C. J. (1999). Parallel stories: A way of contextualizing teacher knowledge. Teaching and Teacher Education(15), 397-411. https://doi.org/10.1016/S0742-051X(98)00062-6

Craig, C. J. (2000). Stories of schools/teacher stories: A two part invention on the walls theme. Curriculum Inquiry, 30(1), 11-41. https://www.jstor.org/stable/3202128

Davis, H. A. (2003). Conceptualizing the role and influence of student-teacher relationships on children's social and cognitive development. Educational Psychologist, 38(4), 207-234. https://doi.org/10.1207/S15326985EP3804_2

DeMitchell, T. A., \& Hambacher, E. (2016, January). Zero tolerance, threats of harm, and the imaginary gun: "Good intentions run amuck". B.Y.U. Educational \& Law Journal, 1-23.

Dupper, D. R. (2010). Does the punishment fit the crime? The impact of zero tolerance discipline on at-risk youths. Children and Schools, 32(2), 67-69.

Ellis, C. S. (2012). Interactive interview. In L. M. Given (Ed.), The SAGE Encyclopedia of Qualitative Research Methods (pp. 444-445). Thousand Oaks, CA: SAGE Publications, Inc.

Froehele, C. (2012, December 19). Equality: to a conservative/to a liberal. [Graphic image]. Google+. https://plus.google.com/+CraigFroehle/posts/AdKcNKesXwa

Froehle, C. (2016, April 14). The evolution of an accidental meme. Retrieved from Medium: https://medium.com/@CRA1G/the-evolution-of-an-accidental-meme-ddc4e139e0e4

Gollnick, D. M., \& Chinn, P. C. (2016). Multicultural education in a pluralistic society (10th ed.). Columbus, $\mathrm{OH}$ : Pearson.

Gonzalez, T. (2012). Keeping kids in schools: Restorative justice, punitive discipline, and the school to prison pipeline. Journal of Law \& Education, 41(2), 281-335.

Gregory, A., Skiba, R. J., \& Noguera, P. A. (2010). The achievement gap and the discipline gap: Two sides of the same coin? Educational Researcher, 39(1), 59-68. DOI:

10.3102/0013189X09357621

Heer, K. (2015). I thought you were one of us! Triumphs and crises when teaching your own. Review of Education, Pedagogy, and Cultural Studies, 37(4), 359-372. https://doi.org/10.1080/10714413.2015.1065622

Herbert, W. (2015, January 13). The discipline gap: Race in the classroom. Association for Psychological Science: https://www.psychologicalscience.org/news/were-onlyhuman/the-discipline-gap-race-in-the-classroom.html

Kauffman, J. M. (2002). Education deform: Bright people sometimes say stupid things about education. Lanham, MD: Scarecrow Education, Inc.

Kersey-Matusiak, G. (2004). The power of one voice: why faculty of color should stay in small, private, predominantly white institutions. In D. Cleveland, A long way to go:

Conversations about race by African American faculty and graduate students (pp. 120130). Peter Lang, Inc. 
Krstic, K. (2015). Attachment in the student-teacher relationship as a factor of school achievement. Teaching Innovations, 28(3), 167-188.

Ladson-Billings, G. (2001). Crossing over to Canaan: The journey of new teachers in diverse classrooms. San Francisco, CA: Jossey-Bass.

Lei, J. L. (2006). Teaching and learning with Asian American and Pacific Islander students. Race Ethnicity and Education, 9(1), 85-101.

McCormick, M., O'Connor, E., Cappella, E., \& McClowry, S. (2013). Teacher-child relationships and academic achievement: A multilevel propensity score model approach. Journal of School Psychology, 51, 611-624. https://doi-org.srvproxy2.library.tamu.edu/10.1016/j.jsp.2013.05.001

Milner, R. H. (2015). Research on classroom management in urban schools. In E. Emmer, \& E. J. Sabornie, Handbook of Classroom Management (2nd ed., pp. 558-618). New York, NY: Routledge.

Milner, R., Flowers, L., Moore, E., Moore, J., \& Flowers, T. (2003). Preservice teachers' awareness of multiculturalism and diversity. The High School Journal, 87(1), 63-70. https://doi.org/10.1353/hsj.2003.0018

Miron, L. F., \& St. John, E. P. (Eds.). (2003). Reinterpreting urban school reform: Have urban schools failed, or has the reform movement failed urban schools? Albany, NY: State University of New York Press.

Mitchell, D. S. (2014). Zero tolerance policies: Criminalizing childhood and disenfranchising the next generation of citizens. Washington University Law Review, 92(2), 271-323.

Mongan, P., \& Walter, R. (2012). "The road to hell is paved with good intentions": A historical, theoretical, and legal analysis of zero-tolerance weapons policies in American schools. Preventing School Failure, 56(4), 232-240. https://doi.org/10.1080/1045988X.2011.654366

Moore, F. M. (2008). Positional identity and science teacher professional development. Journal of Research in Science Teaching, 45(6), 684-710.

Murray, C., \& Malmgren, K. (2005). Implementing a teacher-student relationship program in a high poverty urban school: Effects on social, emotional, and academic adjustment and lessons learned. Journal of School Psychology, 43(2), 137-152. https://doi.org/10.5937/inovacije1503167K

Narinasamy, I., \& Mamat, W. H. (2013, December 26). Caring teacher in developing empathy in moral education. Malaysian Online Journal of Educational Science, 1(1), 1-19.

National Center for Education Statistics. (2017). Characteristics of public elementary and secondary school teachers in the United States: Results from the 2015-2016 national teacher and principal survey. Retrieved from Institute of education sciences: https://nces.ed.gov/pubsearch/pubsinfo.asp?pubid=2017072REV 
National Center for Education Statistics. (n.d.). Fast Facts: Back to school statistics. (U. D. Education, Producer) Retrieved October 18, 2018, from Institute of Education Sciences: https://nces.ed.gov/fastfacts/display.asp?id=372

Nelson, L. (2015, October 31). The hidden racism of school discipline, in 7 charts. Retrieved from Vox: https://www.vox.com/2015/10/31/9646504/discipline-race-charts

Nganga, L. (2015). Culturally responsive and anti-biased teaching benefits early childhood preservice teachers. Journal of Curriculum and Teaching, 4(2), 1-16.

Porter, T. R. (2015, March). The school-to-prison pipeline: The business side of incarcerating, not educating, students in public schools. Arkansas Law Review, 68(1), 55-81.

Ravitch, D. (2014). Hoaxes in education policy. The Teacher Educator, 49(3), 153-165. https://doi.org/10.1080/08878730.2014.916959

Romo, V. (2016, June 7). How to change White teachers' lenses. Retrieved from Slate: http://www.slate.com/articles/life/tomorrows_test/2016/06/how_white_teachers_ca n_become_culturally_competent.html

Roorda, D. L., Koomen, H. M., Spilt, J. L., \& Oort, F. J. (2011). The influence of affective teachers-student relationships on students' school engagement and achievement: $A$ meta-analytic approach. Review of Educational Research, 81(4), 493-529.

Sabol, T. J., \& Pianta, R. C. (2012). Recent trends in research on teacher-child relationships. Attachment \& Human Development, 14(3), 213-231. http://dx.doi.org/10.1080/14616734.2012.672262

Schiff, M. (2018). Can restorative justice disrupt the 'school-to-prison pipeline?' Contemporary Justice Review, 21(2), 121-139. https://doi.org/10.1080/10282580.2018.1455509

Skiba, R. J. (2014). The failure of zero tolerance. Reclaiming Children \& Youth, 22(4), 27-33.

Steinberg, L. (2005, February). Cognitive and affective development in adolescence. TRENDS in Cognitive Sciences, 9(2), 69-74. https://doi-org/10.1016/j.tics.2004.12.005

U.S. Department of Education. (2016). The state of racial diversity in the educator workforce. U.S. Department of Education, Office of Planning, Evaluation and Policy Development, Policy and Program Studies Service, Washington, D.C.

Villegas, A., \& Lucas, T. (2002). Preparing culturally responsive teachers: Rethinking the curriculum. Journal of Teacher Education, 53(1), 20-32.

Wilde, S. (2013). Care in education: Teaching with understanding and compassion. New York, NY: Taylor \& Francis. 